\title{
Effect of Using the Financial and Moral Incentive in Achieving Job Satisfaction for the Employees at Ministry of Environment
}

\author{
Dr, Basel Al-Qdudah
}

\begin{abstract}
This study aimed to know effect of using the material and moral incentives in achieving Job satisfaction of the employees at Ministry of Environment.

The study used the descriptive analytical method through a sample consisted of (196) individual and used the questionnaire as the instrument for data collection, after conducting the statistical process the study reached the following:

The presence of differences with statistically significance at significance level $(a \leq 0.05)$ between means of the study sample individuals' answers about degree of using the material and moral incentives in Ministry of Environment and achieving Job satisfaction attribute to gender and age.

The presence of differences with statistically significance at significance level $(a \leq 0.05)$ between means of study sample individuals answer about degree of using the material and moral incentives in Ministry of Environment of achieving Job satisfaction attribute to scientific qualification and years of experience.

The study recommended more studies about material and moral incentives.
\end{abstract}

Keywords: Material and Moral Incentives, Job Satisfaction, Ministry of Environment.

DOI: $10.7176 / \mathrm{EJBM} / 11-2-06$

\section{Introduction:}

In modern era has witnessed more developments in all fields due to the rapid knowledge and technological developments, which pushed the organizations from different types to pay attention to human resources in developing the work procedures and improving the institutional performance.

This cannot be achieved without interest in the modern training methods to equip human resources with the positive skills, behaviors and attitudes to achieve the desired goals using the effective methods.

Business organizations are paying greater interest in employees training process, perceiving that investment in human resources has the potential to increase production levels and improving level of the services, through employees enjoying relevant knowledge and skills, to increase their motivation for work, and raising the performance efficiency generally (Aqeeli, 2016).

Financial and moral incentives are considered one of the most important administrative activities aims at raising work methods and productivity, moral and material Incentives are effective tool for treating many problems the organizations are suffering from in all fields, and considered instrument from the development instrument aim at change and development (Abdalwahab, 2015).

Also, Job satisfaction represents great important for the individuals, and a motive for them to evaluate distinguish levels of performance and feeling of satisfaction about this performance.

\section{Materials and Moral Incentives:}

According to (Byars\& Rue, 2016), incentives represent "that general basic attitude of the individuals toward the work, and the organizational rewards system is often considered an influencing indicator and important for the individuals in the organizations".

(Robbins, 2001, P. 22) considered incentives as general attitude to the nature of the work regarding the differences taking place between the rewards volume the employees receive from the organization, and between the rewards volume they expect to receive.

(Luthans, 2015) sees that "incentives have important dimensions represents in reflecting the emotional dimension in the employees toward the nature and atmosphere of the work in the organization".

In the same frame, (Hasan, 2002, P: 161), identifies incentives as leading to satisfy the individual about specific behavior according to the performance the administration require".

Al-anqari identifies incentives as "a group of factors and external influences prepared by the top management with the goal to influence the employees behavior by motivating and inducing them to raise their productivity empetence (Al-anqari, 2015,P: 13).

\section{Importance of the Incentives:}

Administrative organizations benefit from applying the incentives in many issues appear through focusing the efforts and perceiving their feasibility and on the employees achievements. This require from the management to know the reality and the productivity, and sides of deficit and the required changes, through the incentives that highly contribute to show the evaluative data for these basic sides inside the administrative organization (Ostroff, 


\section{Types of the incentives:}

The most important types are:

\section{a- Incentives regarding their goals:}

They are divided into two parts:

1. Good performance: These incentive are given for the normal or good performance, this is what required by the classical theories in the management, since it is expected from the individual to increase the normal or good performance, if the performance level decreased over time to reach the minimum level of the performance which preserves the Job for the individual to receive his salary and the determined incentives, which means the employee might continue in his Job as a result of his minimum level of performance that guarantee not to finish his work.

The same as in the beurocratic organizations, since the good performance incentives like promotion, recognition and premiums are often determined based on the individual commitment to the determined performance, and its unexpected from him to increase or develop or renew it (Yaghi, 2015).

2. The Excellent Performance: Here incentives are given in return of the excellent performance which includes innovation and renewal, this is what the modern trends in the management are seeking for like management by the objectives, which includes incentives provided by the management for the excellent and innovative performance in which the employee adds to work something new, such as creating a new method for performance saving some time and effort, or facilitating the procedures and reducing work's steps, or achieving reduction in the costs, or introducing to the management useful suggestions.

Of course, the innovation sides differ from one organization to another, and from one profession to another, the management determines the innovations, excellence and renewal aspects in light of its specific field and the surrounding environment for providing the special incentives (Al-wabel, 2005, P:58).

\section{b- Incentives Regarding Their Nature and Value}

\section{1- Financial Incentives:}

These forms of incentives are multiple and differ in their forms from one sector to another, these incentives respects in the financial rewards, the cash financial incentives is considered one of the most important incentives at this time, because the cash money satisfy's almost all of the human needs, with tangible effect comparing with other means (Haikal, 2013).

\section{2- The moral incentives:}

Moral incentives are considered one of the most important pillars in the incentives system placed by the institution without them the picture of the incentives will not be complete to encourage the work and increase the performance inside the institution, because the human is social in his nature and cannot live far from other's respect and consideration for him.

Also, the employee has many immaterial requirements, these requirements differ from one person to another, but it is possible for limiting these needs and requirements in the need for security, position, status, belonging, and the good relations with the peers and bosses in their need for respect, and respect of others for him to have the feeling of self-trust, ability, and efficacy, in contrast, deficit in these needs might create in him the feeling of weakness and frustration (Hareem, 2003).

\section{c- Incentives Regarding The Related Parties (beneficiaries):}

These incentives focus on creating the individual competition spirit, they are provided to specific individual to increase his performance, or as a reward for him for his distinguish performance, leading to the creation of atmosphere of competition between the individuals.

a- Individual incentives: are incentives the individual alone receives as a result of accomplishing specific work, such as "the promotion, reward, and encouragement premiums), (Al-anqari, 2015).

Individual incentives might be positive, negative, financial, or moral. The employee receives an encouragement reward for his excellent work, and receive his boss's recognition in form of thanks letter or participating in decision making or solving specific problem.

Individual incentives are created to satisfy a group of needs in the individuals, whether psychological, social or material (Al-a'di, 2014).

\section{b- The collective incentives}

These incentives focus on the group work, and the cooperation between the employees, such as the healthcare, social care, and immaterial advantages that might be directed to a group of working employees in one administrative unit, or one division, or one management unit to motivate them for improving performance and raising productivity, collective incentives might be positive negative, material or immaterial.

\section{d- Incentives Regarding Their Effect (Effectiveness)}

a- positive incentives: They bear different advantages to the individual if he performs the required work, and provide him with tangible advantage or intangible advantage, they depend on hope, optimism and the aspiration. 
These incentives include all the material and immaterial desires when increasing the production or improving its level, they are considered the best methods in motivating the employees in most cases, because the disseminate a relevant healthy atmosphere at work to include the greater segment of the employees.

Positive incentives develop creativity and innovation spirit at work in the employees, because they are in harmony with the employee's desires that leave some positive results on the work's course, such as the cash rewards granted to the employees for performing work desires appreciation.

The main goal of this type of incentives is to encourage the working individuals, motivating them on presenting the desired behavior, such as fairness of the basic salary, granting the competent employees exceptional premiums, work stability and Job security for the employees in the business (Haikal, 2013).

\section{b- The Negative Incentives:}

The negative incentive includes a form of punishment, this punishment makes the individuals fear repeating the mistake to avoid the punishment.

From the practical side, the negative incentive does not motivate the work, rather alerting, does not push for cooperation, and teaching the performance, it teaches avoiding the punishment, and how the employee avoids situations resulting in punishment.

Fear from discharged from the work is not a negative mean for control and monitoring from the cycological side, its leads the individual to exert his maximum limit of energy in order not to discharged from the work (Hasan, 2002).

\section{Concept of Justification:}

Many definitions of Job satisfaction are multiple, they reflect their owners' point of views, from Job satisfaction definition "The happiness feelings resulting from the individual's perceptions about a specific Job which give him value at work and what surround it" (Ghareeb, 2014: 175).

Also, identified as "satisfying the individual's needs resulting from many factors, might relate with the business environment, with the Job the individual is occupying which makes the individual satisfy's with his work, desires and aspirations (Abdalmonem, 2012: 173).

The researcher can identify Job satisfaction as "one of the resulting phenomenon from the presence of self-goals and aspirations the employees seek for achieving them to achieve their job satisfaction".

There are many factors affecting the individuals Job satisfaction (Ben Tari, 2016):

First - Group of Personal Factors: The are divided into:

1- Factors related to the skills and capabilities that the individuals hold, can be analyzed through analyzing the aspects and the specifications.

2- Factors related to the individuals' motivation, and extent of the effect of work motives in the individual. Second: Factors Related to Work Conditions: Might be related with Job design and extent of relevance of the specific duties with the Job with the person's capabilities abilities and attitudes.

Third: A group of factors related with the work environment, such as ventilation, illumination, and other factors.

\section{Literature Review:}

- Arabic Studies:"

Belqeed and Bori (2017) study aimed to know the relationship of incentives with the employees performance level, the study used the descriptive analytical method, study sample consisted of employees in the national company for points in Wahran- Algeria, the questionnaire has been used for data collection, (30) questionnaire were distributed, and after performing the statistical analysis process the study reached a number of results, the most important are: incentives are a group of means employed by the establishment to direct the employees behavior, including their desire to perform specific work or to refrain from it, also the study reached that effectiveness of the incentives cannot be achieved without the presence of clear and complete bond between the employees performance and receiving the incentives, also their effectiveness depend on the extent of the individual's desire to receive it, and extent of perceiving their fairness, and most types of incentives are considered the positive motive for human resources' performance by raising and improving it in the establishment.

Ben Tari (2016) study aimed to address effect of developing the occupational path in Job satisfaction in Bascra Establishment for textile and supplies, also the study aimed to know effect of the sample's attitudes in the establishment toward the important of developing the occupational path in achieving Job satisfaction of the employees in the establishment. The researcher used the descriptive, analytical method, also the questionnaire has been used as the instrument for data collection.

Study sample consisted of (100) individuals from the employees. After conducting the statistical analysis process the study reached the presence of medium level for developing the occupational path in the researched organization, also the study reached that the occupational path in its different dimensions was at high degree. 
The study recommended the necessity for conducting more studies to connect between the occupational path and other variables.

Miloodi and Hamadi (2016) study aimed to know effect of incentives and their influence on the employees performance level in the telecommunication Establishment in Algeria. The study depend on the descriptive analytical method, and used the questionnaire is used for data collection.

Study sample consisted of (100) employee in the establishment. After conducting the statistical analysis process the study reached a number of results, the most important are:

Causes of the good performance are really a group of financial and moral factors, by employing an effective incentive policy by the organization to raise their moral spirit and to push them to exert more effort and improve their performance to achieve this effectiveness for the management.

\section{Foreign Studies:}

Waiyaki (2017) study entitle "Effect of motivation on employee performance: A case of Pam Golding Limited, Nairobi".

This study aimed to investigate effect of incentives on the employees performance in the organizations.

Study population consisted of all employees in "Pam Golding" for real estates in Nairobi, a sample consisted of (50) persons from the employees in the human resources in the company were selected.

After conducting the statistical analytical process the study reached that human resources management in the company uses incentive goals to motivate its employees, also the company permitted its employees determining the goals.

Also the study showed the presence of shortage in regular training and developing of the employees to improve their basic skills and knowledge's, in addition the employees in the company showed their dissatisfaction with the cash incentive packages provided by the company, and the rewards programs were not effective and fair to the employees.

Kemoh (2016) study entitle: "The Impact of Motivation on Employees performance in an organization: A case of UniciefSomalia support center" aimed to determine effect of the incentives on the employees performance. The study used the descriptive analytical research method. Study population consisted of the employees in Unicief Somalia support center.

Study sample consisted of (122) employee, and data has been collected through the use of the questionnaire.

After conducting the statistical analysis process the study reached that the Unicief in Somalia did not use the cash rewards to motivate its employees.

Also, the study showed the company used the non-cash rewards such as the promotion and contribution in the decision making flexibility of work hours, also showed that the employees indicated that the cash money is very important incentive to motivate them towards the work.

\section{Research Problem:}

Through the researcher's nature of work employee in Ministry of Environment, he noticed the presence of a number of indicators of the unfairness in the applied incentives system and methods on the employees in the Ministry especially related to the financial incentives, since the incentives allocated to a specific group of the employees are not based on the law according to the rewards system, rather on the decision makers desires which will leave the negative impact on the employees Job satisfaction and on their morals, this is applies to the moral incentives.

Based on that the study aims to know the applied incentive system on the employees in Ministry of Environment, and the extent of its negative influence on Job satisfaction.

\section{Study Questions:}

This study aims to answer the following questions:

- Are there differences with statistically significance at significance level $(a \leq 0.05)$ between the means of the study sample individuals' answers about the usage of the material and moral incentives in Ministry of Environment and achieving Job satisfaction attribute to gender?

- $\quad$ Are there differences with statistically significance at significance level $(a \leq 0.05)$ between the means of the study sample individuals' answers regarding the use of the material and moral incentives in Ministry of Environment in achieving Job satisfaction attribute to age?

- $\quad$ Are there differences with statistically significance at significance level $(a \leq 0.05)$ between means of the study sample individuals' answers regarding degree of using the financial and reward incentives in Ministry of Environment in achieving Job satisfaction attribute to the scientific qualification?

- Are there differences with statistically significance at significance level $(a \leq 0.05)$ between the means of the study sample individuals' answers regarding degree of using the financial and moral incentives in Ministry of Environment and achieving Job satisfaction attribute to the experience? 


\section{Importance of the study:}

Study important stems from the theoretical and practical sides:

First: The theoretical importance of the study:

The study importance from the theoretical side stems from the information importance will be reached from the previous literature related to using the financial and moral incentives and achieving Job satisfaction.

Second: The practical importance of the study

The practical importance of this study resides in the following segments that will benefit from the study:

1. The researchers through making this studies a nucleus for other similar studies.

2. Those who are interesting in the managerial terms and searching in the relationship between the variables to benefit from the results of this study.

\section{Terms of the researcher:}

Incentives: "A group of factors, methods and procedures performed by the administrative organizations management" (Al-wabel, 2005: 34).

Financial incentives: "Are the financial incentives provided to the employees in Ministry of Environment in return of effort or ad extra work, or for introducing suggestions to environmental projects contribute to improve the environment, generally in the form of cash incentives or annual premiums or cash rewards".

Moral incentives: "Are moral incentives provided to the employees in Ministry of Environment which do not depend on the financial issues, rather depend on moral means such as thanks letters, appreciation certificate or promotions for a work or an effort.

Job satisfaction: The happiness feelings that result from the individuals' perceptions towards specific Job to give it meaning at work and what surrounds it". (Ghareeb, 2014: 175).

\section{Limitation of the study:}

1- Objectivity limits- They represent in knowing the effect of using the financial and moral incentives in achieving Job satisfaction of the employees in Ministry of Environment.

2- Spatial limits: This study is limited to the Jordanian Ministry of Environment.

3- Temporal limits: This research is conducted in the year 2018-2019.

\section{Methodology of the study:}

The researcher used the descriptive analytical method through the questionnaire prepared in light of a number of studies such as Belqaed and Bari (2017). Ben Tari (2016), its validity and stability were confirmed.

\section{Study population and sample:}

Study population consisted of the employees from Ministry of Environment their number according to the latest statistic in (170) employees while the study sample is determined by a random sample of the employees $(80 \%)$ from the total number of the directors, head of divisions and the employees in the ministry (36) employee.

The questionnaire has been distributed to the sample after referring to the related previous studies like Ben Tari (2016), and Olwan (2011) study, then determining its dimensions and wording its relevant clauses.

Validity of the instrument: To conform the questionnaire's validity the researcher introduced it to a group of specialists and university professors within business administration and public administration major to Judge the extent of the linguistic wording, and the relevance of the clauses for what is prepared for, and making the modifications in light of their notes.

Stability of the instrument: To confirm the stability of the instrument, the researcher has applied it to a pioneering sample from outside of the study sample by (30) individuals, and re-applying after two weeks to extract stability coefficient by (test-retest) method and calculating stability coefficient by using Pearson correlation coefficient. 
Table (1)

Internal Consistency Coefficient for the Questionnaire's Dimensions (Cronbach Alpha Coefficient)

\begin{tabular}{|l|c|}
\hline \multicolumn{1}{|c|}{ The Dimension } & Alpha \\
\hline Financial incentives & 0.91 \\
\hline Moral incentives & 0.88 \\
\hline Incentives as a whole & 0.94 \\
\hline Comfort at work & 0.94 \\
\hline Challenges at work & 0.93 \\
\hline Promotion at work & 0.80 \\
\hline Financial reward & 0.92 \\
\hline Sufficient resources, supervision, and the granted authorities & 0.93 \\
\hline The total job satisfaction & 0.95 \\
\hline
\end{tabular}

The table above shows that the study variables have received high stability percentage.

\section{Statistical Treatment:}

The following statistical methods were used:

1. Means and standard deviations to find out the level of the questionnaire's clauses dimensions within the high, medium and law levels.

2. Cronbach Alpha Equation to calculate the stability total coefficient total coefficient.

3. One way ANOVA analysis to extract the differences significances in light of the personal and occupational variables.

4. T-test of a sample and the study results:

\section{The study results:}

Results of answering the first question:

Are there different with statistically significance at significance level $(a \leq 0.05)$ between means of the study sample individuals' answers regarding the use of the financial and reward incentives in Ministry of Environment and achieving Job satisfaction attribute to gender?

\section{Table (2)}

Results of Testing the First Hypothesis

\begin{tabular}{|c|c|c|c|}
\hline $\begin{array}{c}(\mathbf{T}) \\
\text { Calculated }\end{array}$ & $\begin{array}{c}(\mathbf{T}) \\
\text { Tabulated }\end{array}$ & Sig. & Result of the Null Hypothesis \\
\hline 24.77 & 1.96 & 0.000 & Rejection \\
\hline
\end{tabular}

One sample (t-test) isused, it is found that $(\mathrm{T})$ calculated value $=24.77$, greater that its tabulated value, since the decision rule is: accepting (Ho) if its calculated value is less than the tabulated value, and rejecting (Ho) if higher, so the null hypothesis is rejected and accepting the alternative hypothesis, which means there are differences with statistically significance at significance level $(a \leq 0.05)$ between the means of answers regarding the degree of using the financial and moral incentives in Ministry of Environment and achieving Job satisfaction attribute to gender.

Results of answering the second question:

Are there differences with statistically significance at significance level $(a \leq 0.05)$ between means of the study sample individuals' answers attribute to age?

Table (3)

Results of Testing the Second Hypothesis

\begin{tabular}{|c|c|c|c|}
\hline $\begin{array}{c}(\mathbf{T}) \\
\text { Calculated }\end{array}$ & $\begin{array}{c}(\mathbf{T}) \\
\text { Tabulated }\end{array}$ & Sig. & Result of the Null Hypothesis \\
\hline 23.83 & 1.69 & 0.000 & Rejection \\
\hline
\end{tabular}

One sample (t-test) is used, it and the table above shows that $(\mathrm{T})$ calculated value $=23.83$, greater that its tabulated value, so the null hypothesis is rejected and accepting the alternative hypothesis, which means there are differences with statistically significance regarding the use of the financial and moral incentives in Ministry of Environment and achieving Job satisfaction attribute to scientific qualification.

\section{Table (4)}

Results of Testing the Third Hypothesis

\begin{tabular}{|c|c|c|c|}
\hline $\begin{array}{c}(\mathbf{T}) \\
\text { Calculated }\end{array}$ & $\begin{array}{c}(\mathbf{T}) \\
\text { Tabulated }\end{array}$ & Sig. & Result of the Null Hypothesis \\
\hline 24.359 & 1.96 & 0.000 & Rejection \\
\hline
\end{tabular}


One sample (t-test) is used, the table above shows that $(\mathrm{T})$ calculated value $=24.359$, greater that its tabulated value, so we reject the null hypothesis and accept the alternative hypothesis, which means there are differences with statistically significance attribute to the scientific qualification.

Results of answering the question: Are there differences with statistically significance at significance level $(a \leq 0.05)$ between means of the study sample individuals' answers regarding degree of using the financial and moral incentives in Ministry of Environment and achieving Job satisfaction attribute to years of Experience?

Table (5)

Results of Testing the Third Hypothesis

\begin{tabular}{|c|c|c|c|}
\hline $\begin{array}{c}(\mathbf{T}) \\
\text { Calculated }\end{array}$ & $\begin{array}{c}(\mathbf{T}) \\
\text { Tabulated }\end{array}$ & Sig. & Result of the Null Hypothesis \\
\hline 23.83 & 1.93 & 0.000 & Rejection \\
\hline
\end{tabular}

One sample (t-test) is used, andthe table above shows that $(\mathrm{T})$ calculated value $=23.83$, greater that its tabulated value.

So, the null hypothesis is rejected and accepting the alternative hypothesis, which means the presence of differences attribute to years of experience.

\section{Inferences:}

The presence differences with statistically significance at significance level $(a \leq 0.05)$ between means of the study sample individuals' answers regarding degree of using the financial and moral incentives in Ministry of Environment and achieving Job satisfaction attribute to gender, age and scientific qualification.

\section{Recommendations:}

Based on the results, the study recommending:

1. Ministry of the Environment should conduct meetings and workshops to develop the employees and clients culture to improve their ability to benefit from the skills the have acquired.

2. Ministry of the Environment should send the employee in training courses to acquire the required skills to provide better services to the clients.

3. Ministry of the Environment should make available the publications, periodic and the organizing rosters which show the nature of the provided services in the Ministry.

4. This study might be a nuclear for other similar studies to the researchers in the management field.

\section{List of references}

- AbdalMonem, O (2012). A Proposed model for developing the occupational path as an approach to enhance Job satisfaction and commitment: A field study, Journal of New Horizons, Vol. 1, Number 2, PP. 1-35.

- Abdalwahab, A. (2015). Strategic Management and Developing the human resources, Amman: Dar AlMaseera for Publication and Distribution.

- Abendschein, Lori ,(2004), "Rewards and Recognition: An Assessment of Strategies to Reain and Motivate Employees in Institutions of Higher Education", State University of New York Empire State College, Dissertation Abstract Internationals, P. 88 (AAT 1419672).

- Al-Aidi, K. (2014): "Effect of the incentives on the performance in the public establishment for the cotton industries in Iraq", Unpublished Master Thesis, Al-Al Bay University, Al-Karak, Jordan.

- Al-Anqari, A. (2015). "Incentives systems and their role in raising the employees performance level: A Field study of the employees in Al-Riyad Region" Unpublished Master Thesis Nayef Arab Academy for the security sciences, Al-Riyadh, Kingdom of Saudi Arabia.

- Al-Qaryooti, M. \& Al-Anzi, A. (2004): "Administrative Development Efforts in Kuwait: A Field Evaluative Study" Journal of Public Management, Vol. 3, Num. 44, PP. 1-34.

- Al-Wabel, A. (2005). "Role of the Financial and moral incentives in raising the level of the employees performance from the point of view of the General security officers participated in Al-Haj Season in Kingdom of Saudi Arabia". Unpublished Master Thesis, Nayef Arab University for the security sciences, Al-Riyadh, K.S.A.

- Aqeeli, Omar (2016), Contemporary Management of the Human Resources, Amman- Jordan, Dar Wa'el for Publication and Distribution.

- Ban Tari, Haleema (2016), Effect of developing the occupational path in Job satisfaction: A case study of the Textile, and installation establishment in Bescra. Unpublished Master Thesis, university of Bescra, Algeria.

- Belqaed, A \&Boori, Sh. (2017): Relationship of incentives with the employees level of performance: A Field study in the National Establishment of paints - Wahran Unit, Journal of North Africa Economics, Vol. 17, Number 1, PP. 255-270.

- $\quad$ Byors, L.L., and L.W. Rue.,(2016), "Personnel Management: Concepts and Applicatios" , Philadelphia: W.B. 
Saunders.

- Ghareeb, H. (2014). Managing the occupational paths and its effects on the organizational commitment: A comparative study, Unpublished Doctoral Dissertation, Damascus University, Damascus - Syria.

- Haikal, M. (2013), "Effect of the incentives on the Management and the production effectiveness", Journal of the Management, Vol. 1, Num, 4, PP. 1-45, Cairo - Egypt.

- Harem, H. (2003). "Organizational Behavior: Individuals Behavior in the Organizations". Dar Zahran for Publication and Distribution, Amman- Jordan.

- Hasan , M. (2002). "Skills of Managing the Human Behavior: Requirements for the behavior continuous updating, $1^{\text {st }}$ ed, center for performance development, Cairo, Egypt.

- Kemoh, L. (2016). The impact of Motivation on employees performance in an organization: A Case of Unicief Somalia support centre Nairobi, Unpublished thesis of Degree in Executive Master of Organizational Development (EMOD) UNITED STATES INTERNATIONAL UNIVERSITY- AFRICA

- Meeloodi, A \&Hammodi, W. (2016). Incentives and their influence on the employees performance in the Telecommunication Establishment in Algeria, Unpublished Master Thesis, University of Al-TaherMawlai, Algeria.

- $\quad$ Ostroff, C. ,(2015), "The Relationship Between satisfaction, Attitudes, And Performance: An Organizational Level Analysis" ,Journal of Applied psychology, December, pp. 963 - 674.

- Waiyaki, E. (2017) Effect of motivation on employee performance: a case of Pam Golding Limited, Nairobi, Unpublished thesis of Degree of Master of Science in Organizational Development (MOD) UNITED STATES INTERNATIONAL UNIVERSITY - AFRICA

- Yaghi, M. (2015). "Public employee evaluation of the incentives in the Jordanian Public Departments, A Field Comparative Study” Arab Organization Publications for the Managerial Sciences, Amman, Jordan. 